Thorax 1984;39:583-587

\title{
Variability of peak flow in wheezy children
}

\author{
IDA JOHNSTON, HR ANDERSON, S PATEL
}

From the Department of Clinical Epidemiology and Social Medicine, St George's Hospital Medical School, London

ABSTRACT A study of peak flow variability was carried out among a population sample of 63 wheezy children aged 9-11 years. Recordings were made over 12 days at three times during the day-first thing in the morning, on returning home from school and at bedtime. Eighty nine per cent of the children had symptoms during the diary period. The mean amplitude (difference between the highest and lowest daily peak flow values) was $17 \%$ of the mean daily value (range $4-48 \%$ ). By cosinor analysis the amplitude was $12 \%$ of the mean value (range 1-53\%). In $65 \%$ of the children the lowest point of the daily rhythm as determined by cosinor analysis lay between midnight and 8am; the rhythm was, however, statistically significant in only fourteen individuals $(22 \%)$. These levels of variability are considerably lower than those previously reported in hospital based studies of adult asthmatics. As a method of demonstrating variable airflow obstruction, which is the defining physiological characteristic of asthma, the use of a peak flow diary alone appears to be of limited value in children.

There is a poor correlation between symptoms and the degree of airflow obstruction in asthmatic patients. ${ }^{1-3}$ The measurement of peak expiratory flow rate (PEFR) has therefore been recommended as an aid in the diagnosis and assessment of the severity of asthma and in monitoring the response to treatment. ${ }^{4-7}$ Serial measurement of PEFR is recommended since single recordings of PEFR cannot measure the variability of airflow obstruction, which is the underlying physiological characteristic of asthma. ${ }^{589}$

Before serial PEFR recordings can be interpreted it is essential to know what levels of variability are to be expected in both normal and asthmatic subjects. The rhythms and degrees of variability of PEFR in adult asthmatics have been investigated ${ }^{10} 11$ but there have been no similar studies in children, despite the extensive use of serial PEFR recordings in drug trials among asthmatic children. ${ }^{1213}$ Furthermore, the studies of adult asthma have been carried out in patients who are in hospital or attending outpatient clinics ${ }^{111415}$ and these patients may not be representative of asthmatics in the general population. Finally, there is no general agreement on which, if any, of the several methods of describing

Address for reprint requests: Dr IDA Johnston, Chest Unit, Whittington Hospital (Highgate Wing), London N19 5NF

Accepted 10 February 1984
PEFR variability is the most useful..$^{61617}$ A recent article with wide circulation in Britain stated that self monitoring of PEFR was useful in certain circumstances but gave no guidance about how the results should be expressed or interpreted. ${ }^{7}$ We have examined some of these questions by analysing peak flow diaries obtained from a community survey of 9-11 year old wheezy children in a London borough.

\section{Methods}

A prevalence survey of asthma and wheezing illness was carried out in Croydon schoolchildren by a postal screening questionnaire sent to parents. Subsequently a representative sample of parents of children with current asthma or wheezing was interviewed at home. The methods and results of the screening survey and home interview have been reported. ${ }^{18} 19$ At the time of the home interview parents whose children had wheezed in the month before the interview were asked to complete a two week symptom diary. Later those who had successfully kept the diary were asked to complete a second symptom diary together with a peak flow diary.

Using a Mini Wright Peak Flow Meter ${ }^{20}$ (Clement Clarke International Ltd), each child recorded the results of three blows at each of three times in the day for 12 days. The times of recording, which were linked to the child's daily routine, were: on getting 
up in the morning, on returning from school, and before going to bed. For cosinor analysis these times were defined as $8 \mathrm{am}, 4 \mathrm{pm}$, and $9 \mathrm{pm}$ respectively. The peak flow diaries were performed in the autumn and winter months from October to March. At the start of the diary period a trained field worker, who visited the family at home, demonstrated the correct use of the meter to the parents and children and measured the child's height to the nearest centimetre. Recordings of PEFR supervised by the field worker were made at the start of the diary period, at its midpoint and at the end, to ensure that the correct technique was being maintained. The symptom diary recorded four symptoms, each on a four point scale from 0 to 3: "wheeze last night," "wheeze today," "activity restricted today," and "cough today." Parents were asked to continue the child's usual treatment as prescribed and record this in the diary. At the end of the 12 days parents completed a small questionnaire about their child's symptoms and disability over the diary period.

The highest of each set of three recordings of PEFR was selected for analysis. The overall mean PEFR (the 12 day mean) was expressed as a percentage of predicted. ${ }^{21}$ The variability in PEFR was calculated in four ways:

1 Difference between 12 day means The mean morning, afternoon, and evening values were calculated for each child. Variability was expressed as the difference between the highest and lowest mean as a percentage of the highest mean.

2 Morning dip For each day the difference between the $8 \mathrm{am}$ value and the higher of the $4 \mathrm{pm}$ and 9pm values was calculated and averaged over the 12 day period.

3 Daily variability For each day the amplitude (a) was calculated by the difference between the highest and lowest values, whatever their time of day. This was then expressed as a percentage of both the highest value $(\mathrm{h})$ and the mean $(\mathrm{m})$ for that day. These daily values of $\mathrm{a} / \mathrm{h} \%$ and $\mathrm{a} / \mathrm{m} \%$ were then averaged for the 12 day period.

4 Cosinor variability Cosinor analysis provided a second estimate of $\mathrm{a} / \mathrm{m} \%$ (see below).

To determine whether there was a significant circadian rhythm in PEFR, peak flow readings were regressed as $y=A o+A \cos (2 \pi t / k-\theta)$, where Ao $=$ the mean of $\mathrm{y}, \mathrm{A}=$ half the maximum amplitude, $\theta=$ phase angle in radians, $k$ is the length of cycle, and $t=$ time (hours). This method of fitting a cosinor curve to the data (cosinor analysis) also allows calculation of mean PEFR (cosinor mean), the amplitude as a percentage of the mean (cosinor $\mathrm{a} / \mathrm{m} \%$ ), and the time of the lowest point of the rhythm (bathyphase) of the best fitting curve. ${ }^{11} 22$ Student's $t$ test was used for comparing mean values and the strength of association between the various indices of variability was tested by calculating the correlation coefficient.

\section{Results}

Of the 284 children who were interviewed at home, 102 were reported to have been wheezy in the month before the interview. Eighty five families went on to complete a symptom diary successfully; of these, 64 agreed to keep a peak flow diary. The 64 children were aged 9-11 years and $37(58 \%)$ were boys. The mean height was 138.5 (SD 7.5$) \mathrm{cm}$. There was no significant difference in the ethnic composition ( $81 \%$ caucasian) or social class distribution between those who kept a PEFR diary and the remainder of the 284 children in the home interview survey. Over the 12 months before the home interview $87 \%$ had missed some school because of wheezing illness and $31 \%$ had had more than six weeks' absence for this reason. Most (80\%) had attended their general practitioner or outpatients department over the past year for wheezing illness but only $15(23 \%)$ had ever had a lung function test of any kind. Thirty five children (55\%) were described by their parents as having asthma at the first screening survey. During the diary period only seven of the 64 children were reported in their diaries to be free from respiratory symptoms. In the questionnaire sent to parents at the end of the diary period $22 \%$ were reported to have been well, $36 \%$ slightly wheezy, and $29 \%$ moderately or severely wheezy. During the diary period $36(56 \%)$ children received one or more medications; 24 received bronchodilators, 18 sodium cromoglycate, nine cough medicines, five antibiotics, and four steroids.

One PEFR diary was incomplete and thus not analysed. The group means and indices of variability from the remaining 63 cases are shown in table 1 . The overall mean was less than the predicted normal in 45 children $(71 \%)$ and less than $80 \%$ of the pre-

Table 1 Indices of variability calculated from the peak expiratory flow rate (PEFR) diaries in 63 children

\begin{tabular}{lcl}
\hline & Mean (SD) & Range \\
\hline PEFR & $269(61)$ & $104-374$ \\
Overall mean (1/min) & $90(20)$ & $37-145$ \\
(\% predicted) & $264(63)$ & $94-380$ \\
8am mean (1/min) & $275(61)$ & $106-383$ \\
4pm mean (1/min) & $267(60)$ & $113-379$ \\
9pm mean (V/min) & $8 \cdot 0(5 \cdot 8)$ & $0 \cdot 8-25 \cdot 8$ \\
Difference between means (\%) & $15 \cdot 2(7 \cdot 4)$ & $4 \cdot 2-37 \cdot 8$ \\
Amplitude (\% highest) & $17 \cdot 3(9 \cdot 6)$ & $4 \cdot 3-48 \cdot 0$ \\
Morning dip (1/min) & $21(20)$ & $-33-79$ \\
Cosinor mean PEFR (1/min) & $267(61)$ & $103-372$ \\
Cosinor amplitude (\% mean) & $12 \cdot 0(9 \cdot 5)$ & $1 \cdot 1-52 \cdot 8$ \\
Total symptom score & $17(16)$ & $0-99$ \\
\hline
\end{tabular}




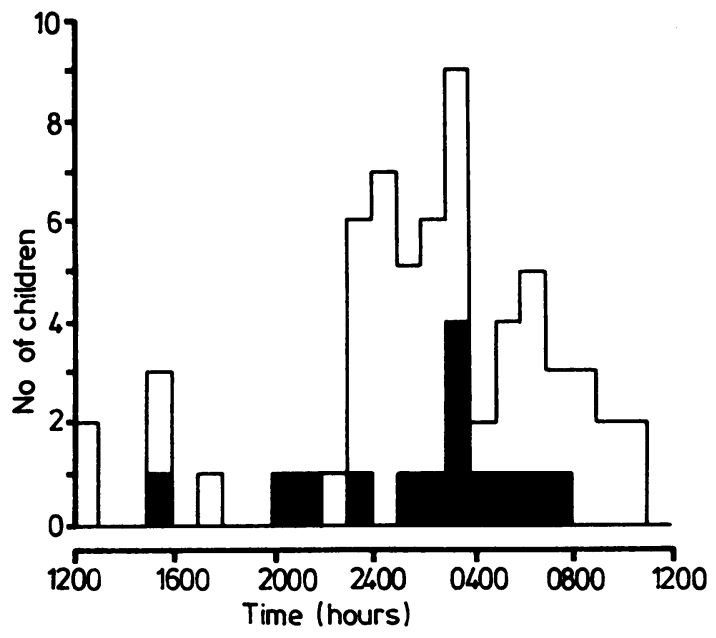

Fig 1 Time of lowest point of peak expiratory flow rate rhythm as predicted by cosinor analysis (hatching indicates those children with a statistically significant rhythm).

dicted value in $15(24 \%)$. For the group as a whole, the 8 am 12 day mean was the lowest, being $4 \%$ lower than the highest mean, which was at $4 \mathrm{pm}$ (table 1). When children were considered individually, $36(57 \%)$ were found to have their lowest mean at $8 \mathrm{am}$, six $(10 \%)$ at $4 \mathrm{pm}$, and $21(33 \%)$ at $9 \mathrm{pm}$. The average value for the whole group of the individual differences between the means was $8.0 \%$ (range $0 \cdot 8-25 \cdot 8 \%$ ).

Of those indices calculated on a daily basis, the mean morning dip was 21 (range -33 to +79 ) $1 / \mathrm{min}$, which represented $8.4 \%$ (range $-11.9 \%$ to
Table 2 Distribution of variability in the 63 children

\begin{tabular}{lllll}
\hline $\begin{array}{l}\text { Percentage } \\
\text { variability }\end{array}$ & $\begin{array}{l}\text { Difference } \\
\text { between 12 } \\
\text { day means }\end{array}$ & $\begin{array}{l}\text { Amplitude } \\
\text { (\% highest) }\end{array}$ & $\begin{array}{l}\text { Amplitude } \\
(\% \text { mean) }\end{array}$ & $\begin{array}{l}\text { Cosinor } \\
\text { amplitude } \\
\text { (\% mean) }\end{array}$ \\
\hline $0-5$ & 28 & 5 & 4 & 20 \\
$6-10$ & 20 & 14 & 14 & 18 \\
$11-15$ & 6 & 21 & 15 & 9 \\
$16-20$ & 8 & 12 & 16 & 6 \\
$21-25$ & 1 & 5 & 5 & 5 \\
$26-30$ & - & 2 & 1 & 2 \\
$31-35$ & - & 3 & 3 & 2 \\
$36-40$ & - & 1 & 4 & -1 \\
$41+$ & - & - & 1 & 1 \\
\hline
\end{tabular}

$+29.8 \%$ ) of each day's mean. The mean values of $\mathrm{a} / \mathrm{h} \%$ and $\mathrm{a} / \mathrm{m} \%$ were $15.2 \%$ (range $4 \cdot 2-37.8 \%$ ) and $17.3 \%$ (range $4 \cdot 3-48.0 \%$ ) respectively.

The cosinor mean was very similar $(267 \mathrm{l} / \mathrm{min})$ to that derived arithmetically and the cosinor $\mathrm{a} / \mathrm{m} \%$ was $12 \cdot 0 \%$ (range $1 \cdot 1-52 \cdot 8 \%$ ). Only 14 subjects had a significant $(\mathrm{p}<0.05)$ rhythm and in these the mean cosinor $\mathrm{a} / \mathrm{m} \%$ was $20.3 \%$, significantly greater $(p<0.001)$ than the $9.6 \%$ for those in whom the rhythm was not significant. The distribution of the lowest point of the PEFR rhythm as predicted by cosinor analysis is shown in figure 1 . While for the majority (41 individuals (65\%)) the lowest point fell between midnight and $8 \mathrm{am}, 10 \%$ had their lowest point in the afternoon. The distribution of the lowest point for those with a significant rhythm appears very similar to that of the whole group.

The distribution of variability for the various indices is shown in table 2 . For the 12 day means variability of more than $20 \%$ was found in only one child. This compares with 14 children for $\mathrm{a} / \mathrm{m} \%, 11$ for $\mathrm{a} / \mathrm{h} \%$, and 10 for the cosinor $\mathrm{a} / \mathrm{m} \%$.

Fig 2 Significance of intercorrelations between the overall mean (absolute and percentage predicted), certain indices of variability, and the total symptom score. ${ }^{*} p<0.05 ;{ }^{* *} p<0.01 ;{ }^{* * *} p<0.001$. 
The indices of variability were compared according to whether the subjects were thought to have asthma by their parents or were regarded as having wheezing illness but not asthma. Those with asthma had a significantly lower mean $\%$ predicted $(86 \% \mathrm{v}$ $96 \% ; p=0.046$ ) but did not differ significantly with respect to $\mathrm{a} / \mathrm{m} \%(19 \% \vee 14 \%)$ or cosinor $\mathrm{a} / \mathrm{m} \%$ $(13 \% \vee 11 \%)$.

The intercorrelations of the various indices are shown in figure 2 . All except the morning dip were negatively associated with the mean PEFR. $\mathrm{a} / \mathrm{h} \%$ is not shown in the figure because it was highly correlated with $\mathrm{a} / \mathrm{m} \%(\mathrm{r}=0.99)$. The total symptom score was found to correlate with $\mathrm{a} / \mathrm{m} \%(\mathrm{r}=\mathbf{0} \cdot 23$, $\mathrm{p}<0.05$ ), but not with the other indices or the overall mean.

\section{Discussion}

This study is the first to describe spontaneous PEFR variability in wheezy children and also the first to examine this among a community sample of wheezy subjects of any age. In view of the suggested wider use of PEFR recording ${ }^{73}$ it was thought important to use recording methods appropriate to routine use in general practice, particularly with regard to the number and timing of the recordings during the day. The number of days chosen was determined by the research resources and the minimum requirements needed for cosinor analysis.

The use of serial measures of ventilatory capacity such as the PEFR for the diagnosis of asthma is logical if we accept that the defining physiological characteristic of asthma is variable obstruction to airflow. If this is so, the first question must concern the way in which this variability should be measured and expressed. We find, however, that this is an area of considerable confusion, with the lack of an agreed terminology as a further impediment. ${ }^{616}$ It is necessary, firstly, to distinguish rhythmic from nonrhythmic variability. One important form of rhythmic variability is the morning dip but this is only useful itself as an indicator of variability if the subject does in fact have a morning fall in PEFR. In this study the 8am mean was the lowest in only $57 \%$ of subjects and our finding that about $10 \%$ had the lowest point of their PEFR rhythm in the afternoon agrees with previous reports. ${ }^{11}$ Thus a substantial proportion of the group did not have a consistent morning fall in PEFR and in these children the measurement of morning dip over 12 days is meaningless. Using the 12 day means we found a $4 \%$ difference between the lowest (8am) and highest (4pm) mean, which compares with the figures of $2 \%$ and $5 \%$ reported in two recent drug trials among children with asthma. ${ }^{1213}$ When the calculation was done for each child's highest and lowest 12 day mean whatever the time of day, the variability increased to $8.0 \%$. These low levels of variability obtained by manipulating the group means cast doubt on the use of such indices in drug trials, particularly if one of the potential benefits of drug treatment might be to reduce variability.

The indices $\mathrm{a} / \mathrm{m} \%$ and $\mathrm{a} / \mathrm{h} \%$ are much better indicators of the magnitude of daily variability, and do not depend on the existence of any rhythm. The mean value for $\mathrm{a} / \mathrm{m} \%(17 \%)$ was, not surprisingly, slightly higher than the mean for $\mathrm{a} / \mathrm{h} \%(15 \%)$ and gave a wider spread. Both indices, however, though easy to measure, are susceptible to biological noise and to bias from unusually large or small variations. ${ }^{6}$ The values here compare with widely differing values for adults of $29 \%(\mathrm{a} / \mathrm{h} \%)$ in asthmatics in hospital,,$^{14} 24 \%(\mathrm{a} / \mathrm{m} \%)$ in chronic bronchitics, ${ }^{24}$ and $7.5 \%(\mathrm{a} / \mathrm{h} \%)$ in outpatient asthmatics. ${ }^{25}$

The strength of cosinor analysis lies in the ability to detect rhythm and indicate its timing without misinterpreting biological noise as true rhythm. ${ }^{6}$ It is not, however, a feasible method of analysis for general practitioners at present since it requires at the least a programmable calculator. We found the mean cosinor $\mathrm{a} / \mathrm{m} \%$ to be only $12 \%$, considerably lower than the $51 \%$ found in asthmatic adultsthough these adults, most of whom were taking steroids, were studied soon after an acute attack requiring hospital admission." But although only $22 \%$ of our subjects had a statistically significant rhythm the distribution of phase was similar to that in the previous study in adults ${ }^{11}$ both in those with and in those without a significant rhythm, suggesting that this feature is common to asthmatics of all ages.

One reason why we found lower levels of variability than those reported for adult asthmatics may be that readings were not taken frequently enough or at the most appropriate times. Moreover, children with seasonal asthma may have been assessed during a relatively quiescent time. The main reason, however, is probably that the children were identified by a cross sectional community survey of wheezing illness rather than by their use of services; O the sample was therefore likely to contain a higher $N$ proportion of milder cases than would be found in studies of patients in hospital or attending outpatients.

These results call into question the usefulness of PEFR diaries for the diagnosis of asthma in chil- $\stackrel{\infty}{\rightarrow}$ dren. The essential problem is that to diagnose asthma is to create a dichotomy (asthma versus non-asthma) while the defining physiological characteristic (variability) is a continuous variable that may overlap with variability in non-wheezy children. To make a cutoff point of, say, $20 \%$, as has 
been recommended in adults, ${ }^{611}$ would have had the effect of classifying as non-asthmatic most of the children in this study despite their considerable morbidity in the diary period. Data are needed on normal children to determine whether a lower cutoff point might be of any value, but it seems likely that the use of PEFR diaries as a means of diagnosis carries a high specificity and low sensitivity. ${ }^{26}$ This is the opposite of what is required in general practice, particularly since it is now established that underdiagnosis and undertreatment of childhood asthma is a major problem..$^{1827}$

We are grateful to Dr MR Hetzel for advice in the planning stage and to Ms J Palmer and Ms S West, the field workers.

\section{References}

1 Cooper DM, Bryan AC, Levison H. Abnormalities in pulmonary function in asymptomatic asthmatic children. Am Rev Respir Dis 1974;109:703.

${ }^{2}$ Rubinfeld AR, Pain MCF. Perception of asthma. Lancet 1976;i:882-4.

${ }^{3}$ Burdon JGW, Juniper EF, Killian KJ, Hargreave FE, Campbell EJM. The perception of breathlessness in asthma. Am Rev Respir Dis 1982;126:825-8.

4 Murray AB, Hardwick DF, Pirie GE, Fraser BM. Assessing severity of asthma with Wright peak-flow meter. Lancet 1977; i: 708.

5 Prior JG, Cochrane GM. Home monitoring of peak expiratory flow rates using Mini-Wright peak flow meter in diagnosis of asthma. $J R$ Soc Med 1980;73:731-3.

' Hetzel MR. The pulmonary clock. Thorax 1981;36:481-6.

7 Anonymous. Self monitoring of peak expiratory flow rate in children. Drug Ther Bull 1982;20:73-4.

${ }^{8}$ Falliers CJ, McCann WP, Ellis EF, Chai H. Clinical methods for the longitudinal study of asthma. $J$ Allergy 1966;37:1-9.

${ }^{9}$ Connolly N, Godfrey S. Assessment of the child with asthma. J Asthma Res 1970;8:31-6.

10 Turner-Warwick M. On observing patterns of airflow obstruction in chronic asthma. $\mathrm{Br} J$ Dis Chest 1977;71:73-86.

" Hetzel MR, Clark TJH. Comparison of normal and asthmatic circadian rhythms in peak expiratory flow rate. Thorax 1980;35:732-8.
12 Edmunds AT, Carswell F, Robinson P, Hughes AO. Controlled trial of cromoglycate and slow-release aminophylline in perennial childhood asthma. $\mathrm{Br} \mathrm{Med}$ J 1980;281:842.

${ }^{13}$ Wilson N, Silverman M. Controlled trial of slo:v-release aminophylline in childhood asthma: are short-term trials valid? Br Med J 1982;284:863-6.

14 Connolly CK. Diurnal rhythms in airway obstruction. $\mathrm{Br}$ J Dis Chest 1979;73:357-66.

is Bagg LR, Hughes DTD. Diurnal variation in peak expiratory flow in asthmatics. Eur $J$ Respir Dis 1980;61:298-302.

${ }^{16}$ Connolly CK. Variation of peak expiratory flow rate. Thorax 1981;36:237.

17 Clark TJH, Hetzel MR. Variation of peak expiratory flow rate. Thorax 1981;36:237-8.

18 Anderson HR, Bailey P, Cooper JS, Palmer JC. Influence of morbidity, illness label, and social, family, and health service factors on drug treatment of childhood asthma. Lancet 1981;ii:1030-2.

19 Anderson HR, Bailey PA, Cooper JS, Palmer JC, West S. Morbidity and school absence caused by asthma and wheezing illness. Arch Dis Child 1983;58:77784.

${ }^{20}$ Wright BM. A miniature Wright peak-flow meter. $B r$ Med J 1978;ii:1627-8.

${ }^{21}$ Cotes JE. Lung function: assessment and applications in medicine. 4th ed. Oxford: Blackwell Scientific Publications, 1979.

${ }^{22}$ Halberg F, Engeli M, Hamburger C, Hillman D. Spectral resolution of low-frequency small-amplitude rhythms in excreted 17-keto steroids: probable androgeninduced circaseptan desynchronisation. Acta Endocrinol 1965; suppl 103:5-54.

${ }^{23}$ Seaton A. Asthma-contrasts in care. Thorax $1978 ; 33: 1-2$.

${ }^{24}$ Dawkins KD, Muers MF. Diurnal variation in airflow obstruction in chronic bronchitis. Thorax 1981;36:618-21

${ }^{25}$ Ryan G, Latimer KM, Dolovich J, Hargreave FE. Bronchial responsiveness to histamine: relationship to diurnal variation of peak flow rate, improvement after bronchodilator, and airway calibre. Thorax 1982;37:423-9.

${ }^{26}$ Fletcher RH. Fletcher SW, Wagner EH. Clinical epidemiology-the essentials. Baltimore: Williams and Wilkins, 1982.

${ }^{27}$ Speight ANP. Is childhood asthma being underdiagnosed and undertreated? $\mathrm{Br}$ Med J 1978;ii:331-2.

${ }^{28}$ Speight ANP, Lee DA, Hey EN. Underdiagnosis and undertreatment of asthma in childhood. Br Med J 1983;286: 1253-6. 